\title{
BMJ Open Development of a Cannabis Assessment Tool (CAT-1) to measure current and lifetime marijuana use among older Veterans
}

\author{
Salomeh Keyhani (D) , ${ }^{1,2}$ Ann Abraham, ${ }^{3}$ Beth Cohen, ${ }^{2}$ Marzieh Vali, ${ }^{2}$ \\ Sodahm Robin Yoo, ${ }^{3}$ Camille Dollinger, ${ }^{3}$ Stacey Steigerwald ${ }^{3}$
}

To cite: Keyhani S, Abraham A, Cohen B, et al. Development of a Cannabis Assessment Tool (CAT-1) to measure current and lifetime marijuana use among older Veterans. BMJ Open 2020;10:e034274. doi:10.1136/ bmjopen-2019-034274

- Prepublication history and additional material for this paper are available online. To view these files, please visit the journal online (http://dx.doi. org/10.1136/bmjopen-2019034274).

Received 13 September 2019 Revised 07 November 2019 Accepted 04 December 2019

Check for updates

(C) Author(s) (or their employer(s)) 2020. Re-use permitted under CC BY-NC. No commercial re-use. See rights and permissions. Published by BMJ.

${ }^{1}$ Department of Medicine, University of California at San Francisco, San Francisco, California, USA

${ }^{2}$ General Internal Medicine, San Francisco VA Medical Center, San Francisco, California, USA ${ }^{3}$ Population Health and Policy Research Group, Northern California Institute for Research and Education, San Francisco, California, USA

Correspondence to

Dr Salomeh Keyhani; salomeh.keyhani@ucsf.edu

\section{ABSTRACT}

Objective To develop a tool to assess current (past 30 days) and lifetime marijuana use in older Veterans. Setting US Veteran's Affairs Healthcare System. Participants 704 older Veterans were screened, 339 completed the initial survey, 100 completed the follow-up. Primary outcome measure Pearson's correlation coefficient to assess strength of association between initial and follow-up survey on measures of current and lifetime marijuana use.

Results Both a 'gram-month' measure of marijuana smoked in the past 30 days $(r=0.83)$ and a frequencybased measure assessing total number of times smoked in the past 30 days were reliable $(r=0.89)$. Both a simple categorical measure of lifetime use (agreement $=85 \%$ ) and a continuous measure of lifetime use $(r=0.82)$ were reliable.

Conclusions The Cannabis Assessment Tool offers a reliable assessment of past 30 days and lifetime assessments of smoking cannabis in older adults.

\section{INTRODUCTION}

Thirty-three states and the District of Columbia have legalised marijuana for medical use while 10 states and the District of Columbia have legalised recreational use. ${ }^{1}$ This has been accompanied by an increase in daily use and cannabis dependence among US adults. ${ }^{2}$ The prevalence of past year marijuana use reached $14.6 \%$ in 2017 and has increased in all age groups including older adults. ${ }^{3}$ Given the increase in use, marijuana assessment tools are needed both to assess and quantify exposure both for research and clinical practice. ${ }^{4}$

The National Academy of Sciences has recently called for the development of robust standardised tools to quantify marijuana use. ${ }^{5}$ Standardised tools are necessary to understand the biological effects of marijuana use. A significant emphasis of prior work has been in the area of assessing frequency of use among patients with cannabis use disorders. ${ }^{67}$
Strengths and limitations of this study

This study provides a reliable method for ascertaining 30-day and lifetime marijuana use.

- The sample for this study was restricted to older male Veterans with coronary artery disease and may not be generalisable to other populations.

- Measures of marijuana use in forms other than smoking were not frequent enough in this sample to assess reliability.

In addition, prior work has focused on use patterns among adolescents. These tools focus on the number of times marijuana was used over a relatively short time period, and therefore, are not useful for assessing lifetime use in older adults. ${ }^{8}$ Tools that focus solely on number of times used over a lifetime may inadequately distinguish between heavy versus light use. There currently are no tools available that retrospectively quantify lifetime use of older adults. As marijuana use becomes more common, tools to quantify past use will become necessary to identify older adults that are at higher risk of adverse cardiovascular or respiratory outcomes related to smoking marijuana.

In addition, previous studies that have quantified marijuana use have included measures of smoking frequency, such as 'jointyears ${ }^{9} 10$ but fail to account for other increasingly popular methods of smoking marijuana (eg, pipes, bongs, blunts, spliffs) and other forms of marijuana use. ${ }^{5}$ Tools that account for all modalities of smoking and other forms of use are necessary to ensure accurate assessments of use.

To address these gaps in the literature, we developed and tested an assessment tool that quantifies current (defined as use in the past 30 days) and lifetime marijuana use in older Veterans. 


\section{METHODS}

\section{Development phase}

Drafting of exposure assessment questions

We identified questions previously used to assess marijuana from federally funded, annual national surveys, including the National Survey on Drug Use and Health, ${ }^{11}$ Monitoring the Future, ${ }^{8}$ the Coronary Artery Risk Development in Young Adults (CARDIA), ${ }^{12}$ other cohorts, ${ }^{9}{ }^{13}$ and through a review of the literature ${ }^{14-18}$ We drafted preliminary questions based on this review.

We interviewed a total of eight professional experts from various fields, including substance use and mental health experts, marijuana dispensary staff located in San Francisco, and marijuana distributors and other industry professionals, to determine how marijuana use is defined. We shared our draft questions and revised them based on feedback from these individuals. Our tool focused on gathering granular information for all commercially available forms of marijuana (smoked, vaped, edibles, concentrates and topicals). For each form, we developed preliminary questions about length of use, frequency of use and number of daily sessions of use.

\section{Cognitive interviews with users}

We conducted cognitive interviews with a convenience panel of 13 current marijuana users identified from the clinic panels of the study investigators (SK, BC) to test the acceptability of the questions and determine if they accurately captured current and lifetime use. Content discussed in these interviews included appropriate language to describe modality of use and how to frame questions about frequency and amount of use.

We found individuals were smoking marijuana via several different modes of consumption (eg, joint, pipe, or bong) and quantity consumed was variable between each mode. Users could estimate the total grams of marijuana they had consumed in the past 30 days, as this is the form in which many users buy marijuana (eg, an eighth of an ounce, a quarter of an ounce, half an ounce), suggesting a metric based on weight could aggregate bud used in different forms of smoking. Frequency of use was another common way to describe quantity of use in past 30 days; however, questions aimed at estimating total frequency of use in the past 30 days were somewhat challenging for non-daily users. Answer choices based on frequency of use in the past week as opposed to in the past month were easier for non-daily users to answer. We also noted that if we did not ask about all forms of marijuana use (joints, pipes, bongs, spliffs, blunts), we may underestimate use and opted to query frequency of use of each form of smoking individually.

We also queried users about ways to quantify lifetime use. Through these interviews it became clear that most marijuana users have many periods of initiating and stopping use in their lives, which makes quantifying lifetime marijuana use more challenging compared with tobacco use. Based on these interviews, we drafted several measures of cumulative lifetime use. The first (known as the 'Narrative' measure) aimed to gather comprehensive detail on distinct periods of marijuana use and periods of non-use over an individual's lifetime (online supplementary appendix questionnaire 1). Participants were asked about frequency and duration of use during each period. We also drafted two simpler lifetime use measures to assess duration of use: (1) 'over the entire period you smoked marijuana, how many years did you smoke marijuana on a daily or near daily basis?' and a categorical measure of lifetime use: (2) 'which category best describes the total number of times you've smoked marijuana over your lifetime? (0-50, 51-500, 501-1000, more than 1000).

We iteratively refined questions based on these interviews. Survey questions were edited to reflect language at an eighth-grade level using online software. ${ }^{19}$ All interviews were administered over the phone and consent was obtained verbally at the beginning of each interview.

\section{Pilot testing of questions used to assess marijuana use}

We pilot tested the questions in a national sample of 105 Veterans with evidence of marijuana use in their chart. All participants contacted were asked the same current use questions, but each Veteran received different forms of the lifetime use measure. Those who had endorsed using marijuana within the last year or more than 50 times in their lifetime completed the follow-up survey within an average of 9 days after the initial survey. Each measure was pilot tested in at least 18 Veterans.

During pilot testing the questions were iteratively improved. Measures of frequency of use in past 30 days were easy for patients to understand. We found offering standardised weight options in the gram-month question improved patient's ability to reliably answer questions between the initial and follow-up survey. The questions for the 'narrative use' were inconsistent between each individual's initial and follow-up testing and were abandoned in pilot testing. In addition, the number of distinct periods of use among participants ranged from 1 to 9 making this approach to marijuana use assessment impractical in research and in clinical practice. The simple lifetime use measure assessing lifetime years of daily or near daily use and the categorical lifetime use questions were easy for patients to answer and were retained for further testing. We were unable to adequately pilot test questions assessing forms of marijuana use other than smoking (eg, vaped, edibles, concentrates, topicals) because of the limited number of older Veterans that had used these forms of marijuana.

\section{Testing phase}

The Cannabis Assessment Tool (CAT-1) (online supplementary appendix questionnaire 2) was developed for an ongoing prospective cohort study (NHLBI R01HL130484-01A1) focused on examining whether smoking marijuana is associated with cardiovascular events among a high-risk cohort (older Veterans with coronary artery disease). The age of the cohort was restricted to reduce the age-related variability in mortality. 
We identified 1085094 Veterans in the Veteran's Health Administration (VA), in May 2017, who had a diagnosis of coronary artery disease (CAD) using International Classification of Diseases-10 codes. We limited the sample to those who had at least two visits in the prior 2 years $(\mathrm{n}=586867)$ to ensure adequate baseline data available in VA data bases. We limited the sample to Veterans between the ages of 65 and 70 to facilitate extraction of data on baseline characteristics from VA servers leaving 140390 Veterans. We excluded Veterans unlikely to be able to provide interviews including those with dementia, those enrolled in hospice or palliative care, those receiving inpatient cancer chemotherapy and those who resided in a nursing home. We excluded Veterans who had died leaving 127337 individuals in the sample. Finally, we further limited the sample to those born between 1948 and 1951 (between the ages of 66 and 68) as this was the target age of our prospective cohort study. The final sample eligible for possible interview included 54935 Veterans. We divided the final sample into two groups: those with terms (marijuana, cannabis) related to marijuana use in their progress notes and those without terms related to marijuana use using a previously developed text processing method. ${ }^{20}$ The text processing algorithm used to search notes is a blunt tool that increases the probability of identifying current or former marijuana users and supports cohort development.

We randomly selected Veterans with a marijuana term in their chart from the previously described sample with the goal of completing at least 100 follow-up surveys with current smokers. We required a total of 704 Veterans to reach recruitment targets (figure 1). We excluded a total of 85 individuals based on chart review using the exclusion criteria previously described and sent a total of 619 recruitment letters. We were unable to contact 165 Veterans and 115 were excluded because they either declined to participate $(\mathrm{n}=98)$ or met an exclusion criterion that was not identified in their medical record (eg, hearing impaired, recently diagnosed with cancer, etc. $(n=17)$. We conducted a follow-up survey among the participants that reported smoking marijuana in the past 30 days. Two interviewers conducted the initial surveys (CD, SRY). Each follow-up survey was conducted by a different interviewer. Consent was obtained verbally at the start of each interview.

\section{Statistical analysis}

All responses (categorical, gram, ounce) for the grammonth question were converted into grams and were treated as a continuous measure. Total frequency of use in the past month were calculated by summing the number of times marijuana was smoked in any form each day. The reliability of each measure was assessed using Pearson's correlation coefficient for continuous data and simple agreement for categorical data. Reliability was reported for all measures that had complete data for more than ten participants in the initial survey and the follow-up. We used R statistical software V.3.5.3 for the analyses.

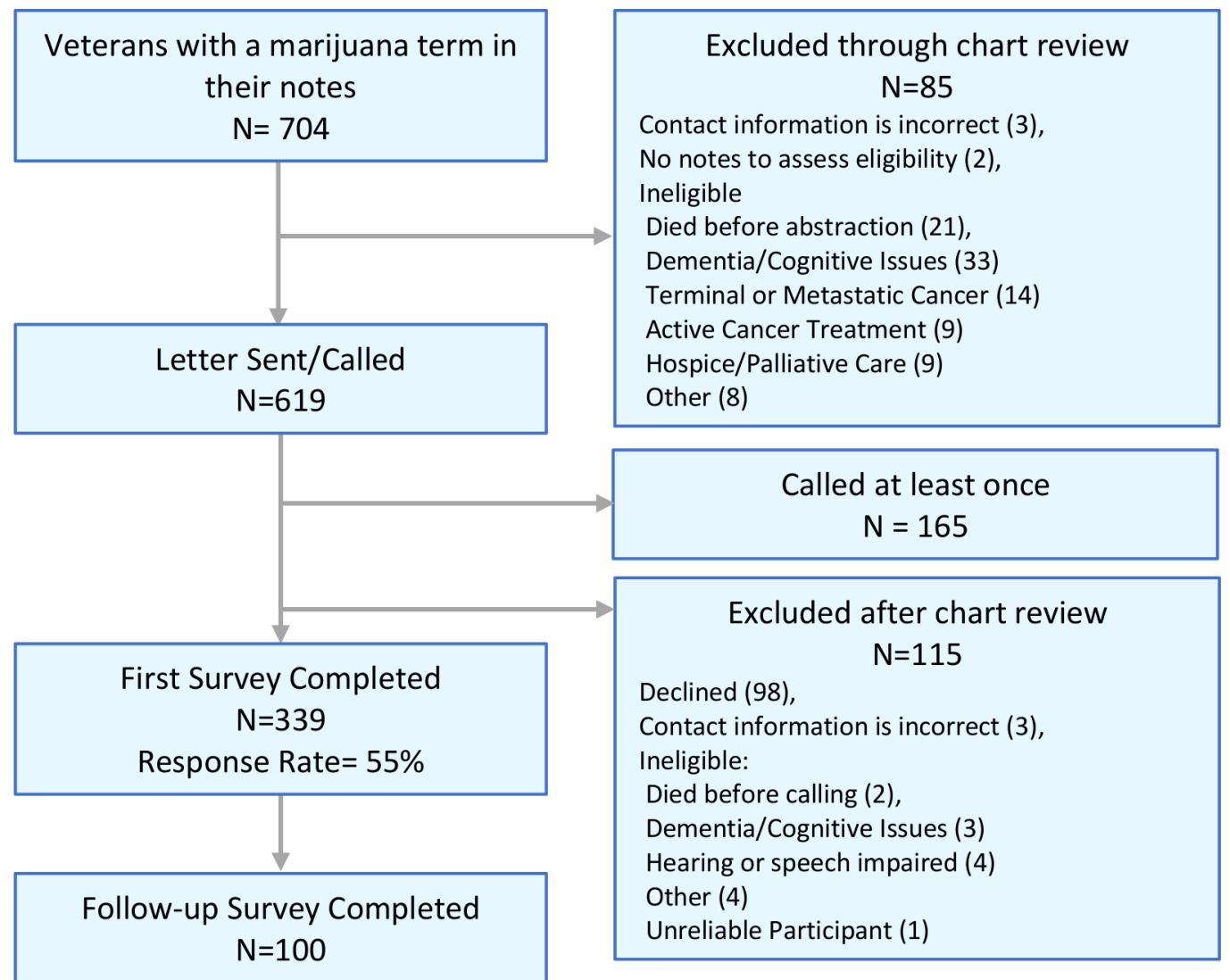

Figure 1 Flowchart of cohort construction from text processing to interview completion. 
Table 1 Cohort characteristics $(n=339)$

\begin{tabular}{|c|c|c|c|}
\hline Variable & $\begin{array}{l}\text { All } \\
\text { participants } \\
n=339\end{array}$ & $\begin{array}{l}\text { Current } \\
\text { marijuana } \\
\text { smoker } \\
n=113\end{array}$ & $\begin{array}{l}\text { Non-current } \\
\text { marijuana } \\
\text { smoker* } \\
\mathrm{n}=226\end{array}$ \\
\hline Age (mean) & 67 & 67 & 67 \\
\hline \multicolumn{4}{|c|}{$\mathbf{N}(\%)$} \\
\hline Male & 330 (97.3) & $113(100)$ & $217(96)$ \\
\hline \multicolumn{4}{|l|}{ Race } \\
\hline White & $246(72.6)$ & $84(74.3)$ & $162(71.7)$ \\
\hline Black & $63(18.6)$ & $16(14.2)$ & $47(20.8)$ \\
\hline Other & $30(8.8)$ & $13(11.5)$ & $17(7.5)$ \\
\hline \multicolumn{4}{|l|}{ Education } \\
\hline $\begin{array}{l}\text { Less than high school } \\
\text { graduate }\end{array}$ & $28(8.3)$ & $8(7.1)$ & $20(8.8)$ \\
\hline $\begin{array}{l}\text { High school diploma } \\
\text { or equivalency }\end{array}$ & $205(60.5)$ & $75(66.4)$ & $130(57.5)$ \\
\hline $\begin{array}{l}\text { College or graduate } \\
\text { degree }\end{array}$ & $106(31.3)$ & $30(26.5)$ & $76(33.6)$ \\
\hline $\begin{array}{l}\text { Married or domestic } \\
\text { partnership }\end{array}$ & $168(49.4)$ & $51(44.7)$ & $117(51.8)$ \\
\hline \multicolumn{4}{|l|}{ Employment status } \\
\hline Working & $27(8)$ & $5(4.4)$ & $22(9.7)$ \\
\hline \multicolumn{4}{|l|}{ Self-reported Health } \\
\hline Excellent & $11(3.2)$ & $3(2.7)$ & $8(3.5)$ \\
\hline Good & $127(37.5)$ & $44(38.9)$ & $83(36.7)$ \\
\hline Fair & $143(42.2)$ & $42(37.2)$ & $101(44.7)$ \\
\hline Poor & $58(17.1)$ & $24(21.2)$ & $34(15)$ \\
\hline \multicolumn{4}{|c|}{ Tobacco smoking (cigarette) } \\
\hline Current & $112(33)$ & $39(34.5)$ & 73 (32.3) \\
\hline Former & $185(54.6)$ & $66(58.4)$ & $119(52.7)$ \\
\hline Never & $42(12.4)$ & $8(7.1)$ & $34(15)$ \\
\hline Ever marijuana use & $287(84.7)$ & $113(100)$ & $174(77.0)$ \\
\hline $\begin{array}{l}\text { Current illicit drug use } \\
\text { (eg, cocaine) }\end{array}$ & $6(1.8)$ & $4(3.5)$ & $2(0.9)$ \\
\hline \multicolumn{4}{|c|}{ Status of legalisation in state of residence } \\
\hline Recreational & $94(27.7)$ & $40(35.4)$ & $54(23.9)$ \\
\hline Medical & $122(36)$ & $49(43.4)$ & 73 (32.3) \\
\hline Non-legal & $123(36.3)$ & $24(21.2)$ & $99(43.8)$ \\
\hline
\end{tabular}

*Includes all participants who endorsed never using marijuana, never smoking marijuana, or not smoking marijuana within the past 30 days.

\section{Patient and public involvement}

No members of the public were involved in the design, or conduct, or reporting, or dissemination of the research.

\section{RESULTS}

\section{Sample characteristics}

The response rate for the initial survey was $55 \%(\mathrm{n}=339)$ (table 1$)$. The cohort was majority male $(\mathrm{n}=330,97.3 \%)$, white $(\mathrm{n}=246,72.6 \%)$ and high school educated or higher $(\mathrm{n}=311,91.7 \%)$. Status of legalisation of marijuana in state of residence was relatively equally distributed among
Table 2 Characteristics of current marijuana smokers

\begin{tabular}{|c|c|}
\hline Variable & smokers ( $n=113$ ) \\
\hline \multicolumn{2}{|l|}{ Forms of current marijuana use } \\
\hline Current smoker & $113(100)$ \\
\hline Current vaper & $10(8.8)$ \\
\hline Current edible user & $19(16.8)$ \\
\hline Current dabber & $4(3.5)$ \\
\hline Current topical user & $8(7.1)$ \\
\hline \multicolumn{2}{|l|}{ Combined tobacco and marijuana use } \\
\hline Blunts & $10(8.8)$ \\
\hline Spliffs & $2(1.8)$ \\
\hline Other & $1(0.9)$ \\
\hline \multicolumn{2}{|c|}{ Forms of smoking (joint, pipe, bong, blunt and/or spliff) } \\
\hline Only one form of smoking & $77(68.1)$ \\
\hline Two forms of smoking & $29(25.7)$ \\
\hline Three or more forms of smoking & $7(6.2)$ \\
\hline \multicolumn{2}{|l|}{ Frequency of smoking } \\
\hline Smokes less than daily & $54(47.8)$ \\
\hline Smokes daily & $59(52.2)$ \\
\hline \multicolumn{2}{|l|}{ Frequency of daily smoking } \\
\hline Once a day & $11(9.7)$ \\
\hline Two times per day & $14(12.4)$ \\
\hline Three or more times per day & $34(30.1)$ \\
\hline
\end{tabular}

the cohort. About $27.7 \% \quad(\mathrm{n}=94)$ were from recreationally legal states, $36.0 \%$ were $(\mathrm{n}=122)$ from medically legal states and $36.3 \%(n=123)$ were from non-legal states.

Concordance of text processing algorithm with reported use

A majority $(84.7 \%, \mathrm{n}=287)$ of the cohort reported marijuana use in their lifetime. Comparison of charts to patient interviews revealed that $40(11.8 \%)$ respondents had a false positive term in their medical record (eg, 'no marijuana use') and 11 (3.2\%) respondents had terms in their chart suggestive of use in the prior year but who denied use in the interview.

\section{Forms of marijuana use in the cohort}

A third of the cohort endorsed smoking marijuana in the past 30 days $(n=113,33.3 \%)$ and were eligible for the follow-up survey. Among the 113 Veterans, 68.1\% $(\mathrm{n}=77)$ endorsed using only one form of smoking, $25.7 \%$ $(n=29)$ endorsed two forms of smoking and 6.2\% ( $n=7)$ endorsed three or more forms of smoking in the past 30 days (table 2).

Among the participants that smoked in the past 30 days, $59(52.2 \%)$ smoked daily. Among the 59 participants that smoked daily in the past 30 days, $11(18.6 \%)$ participants smoked once a day, $14(23.7 \%)$ smoked two times per day and $34(57.6 \%)$ smoked three or more times per day (table 2).

Among current marijuana smokers, $16.8 \% \quad(n=19)$ endorsed current edible use, $8.8 \% \quad(n=10)$ endorsed 
current vaping, $7.1 \%(\mathrm{n}=8)$ endorsed current topical use and $3.5 \%(n=4)$ endorsed current dabbing (also known as concentrate use) (table 2). Over a third of current marijuana smokers $(\mathrm{n}=39,34.5 \%)$ were also current tobacco smokers while over half $(\mathrm{n}=66,58.4 \%)$ were former tobacco smokers (table 1). The average length of time between completion of the initial survey and the follow-up survey was 3 days (range: 1-25 days). The response rate for the follow-up survey was $88.6 \%(n=100)$ (figure 1).

\section{Measure reliability \\ Current use}

The weight-based measure (gram-month) was a reliable measure of current marijuana use $(\mathrm{r}=0.83)$ (table 3$)$. Five individuals provided an alternate method of measurement (eg, tablespoon or teaspoon), which were converted to a weight-based metric (see online supplementary appendix table 1). Two individuals either did not know their answer or refused to answer this method of measurement. An aggregate measure of both frequency of use over the past 30 days and of total quantity of joints, pipes and bongs over the past 30 days were also reliable $(\mathrm{r}=0.78$ and $\mathrm{r}=0.89$, respectively) (table 3 ).

Agreement for all other current use questions, which gathered more specific information about each type of smoked marijuana (eg, joint, pipe, bong) ranged from moderate to very high $(\mathrm{r}=0.63$ to $\mathrm{r}=0.92)$ (table 3$)$.

\section{Lifetime use}

We found that individuals were reliably able to estimate the total number of times they had used marijuana over their lifetime (agreement $=85.0 \%$ ) and the number of years they had smoked on a daily or near daily basis $(\mathrm{r}=0.82)$ (table 4).

\section{Other forms of current marijuana use}

We also asked questions assessing current and lifetime use of forms of marijuana other than smoking. We were unable to pilot test these questions given the low overall prevalence of use in this older population. Preliminary results indicate screener questions assessing whether someone had ever used a specific form or had used a specific form in the past 30 days were reliable although the sample size was small (online supplementary appendix table 2).

\section{DISCUSSION}

We found the 'gram-month' measure and a frequency measure of smoking marijuana in the past 30 days were both reliable means of collecting current marijuana use across different modes of consumption. We also found simple measures of lifetime use were reliable.

The marijuana industry has changed dramatically, and methods used to assess marijuana use in prior cohort studies are no longer adequate. For example, the CARDIA study, which began in 1985 and examined
5115 US adults ages $18-30,{ }^{12}$ and the Dunedin Multidisciplinary Health and Development Study, ${ }^{913}$ which began in 1972 and is still ongoing in its examination of 1037 New Zealanders beginning at birth, assess marijuana exposure by assuming that one joint or pipe a day for every day in a year is equivalent to one 'joint year' and ask only about smoked marijuana. ${ }^{913}$ These measures fail to differentiate users who smoke marijuana more than once a day or use marijuana in forms other than smoking. About $81.4 \%$ of daily marijuana users in our sample smoked marijuana more than once daily. Current assessments of marijuana use must account for marijuana being smoked in forms other than joints, multiple times per day, and in forms other than smoking.

The CAT-1 developed in this study expands on previously established questions by asking not only about frequency of joint smoking, but also the frequency and duration of all other forms in which marijuana is smoked. Even after assessing frequency and duration of all forms of marijuana, it is still difficult to assess the total amount of marijuana an individual has consumed over a given period as the amount of marijuana per product varies. We attempted to address this issue in the CAT-1 by asking directly about the total amount of marijuana an individual has used in the past month, regardless of the form in which the marijuana was smoked. This approach may provide an aggregate estimate of individual use but also has limitations. Five respondents chose to answer the gram-month measure using another weight-based measure while two respondents could not answer in any variation (one respondent endorsed 'don't know' and one respondent refused the question). While the grammonth measure is reliable it is limited by the fact that some individuals could not use the response options offered and had to report use using alternative weight measures. A measure of current use-based frequency of different forms used may be the most relatable measure for individuals to report their use and the easiest one for researchers to use for assessments of exposure. Future work can externally validate the measures by examining if one current use measure is more strongly associated with adverse health outcomes. In addition, future work should also focus on simplifying current use measures, as measures that query patients about all forms of use may be more accurate but may be too long to incorporate into clinical practice.

We also developed reliable lifetime use measures that could be used both in research and in clinical practice. There are no retrospective measures of marijuana use that can be used as assessment tools in clinical practice to identify patients that might be at higher risk of adverse health outcomes. The lifetime-use measures tested in this study lay the foundation for such a tool. Future work focused on validation of these tools can focus on examining whether these lifetime assessment tools can differentiate respiratory and cardiovascular health outcomes among users with a shorter duration of lifetime use compared with longer duration of use. 
Table 3 Reliability of current smoking assessment tools

\begin{tabular}{|c|c|}
\hline Question & Response choices \\
\hline \multirow{11}{*}{$\begin{array}{l}\text { Which of the following categories best } \\
\text { captures the amount of marijuana you } \\
\text { smoked over the past } 30 \text { days? }\end{array}$} & An eighth of an ounce (which is the sa \\
\hline & A quarter of an ounce (which is the sa \\
\hline & A half of an ounce (which is the same \\
\hline & $\begin{array}{l}\text { Three quarters of an ounce (which is } t \\
21 \mathrm{~g} \text { ) }\end{array}$ \\
\hline & An ounce (which is the same as $28 \mathrm{~g}$ ) \\
\hline & Grams \\
\hline & Ounces \\
\hline & Hits \\
\hline & Other \\
\hline & Refused \\
\hline & Don’t know \\
\hline
\end{tabular}

In the last 30 days have you smoked

Joint

a...

Pipe

Bong

Blunt

Spliff

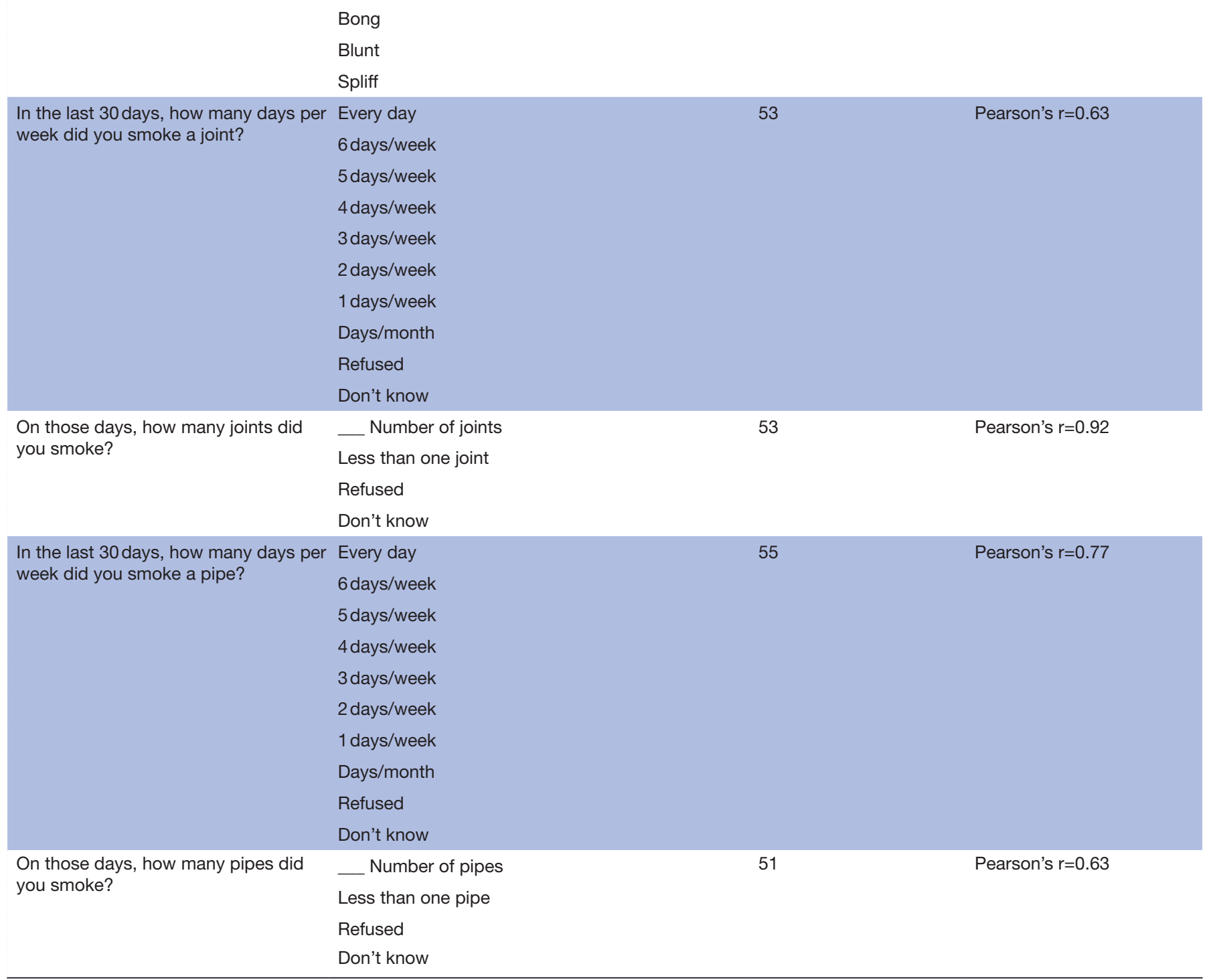

\section{Complete observations Pearson's $r$ or agreement}

Pearson's $r=0.83$

Continued 
Table 3 Continued

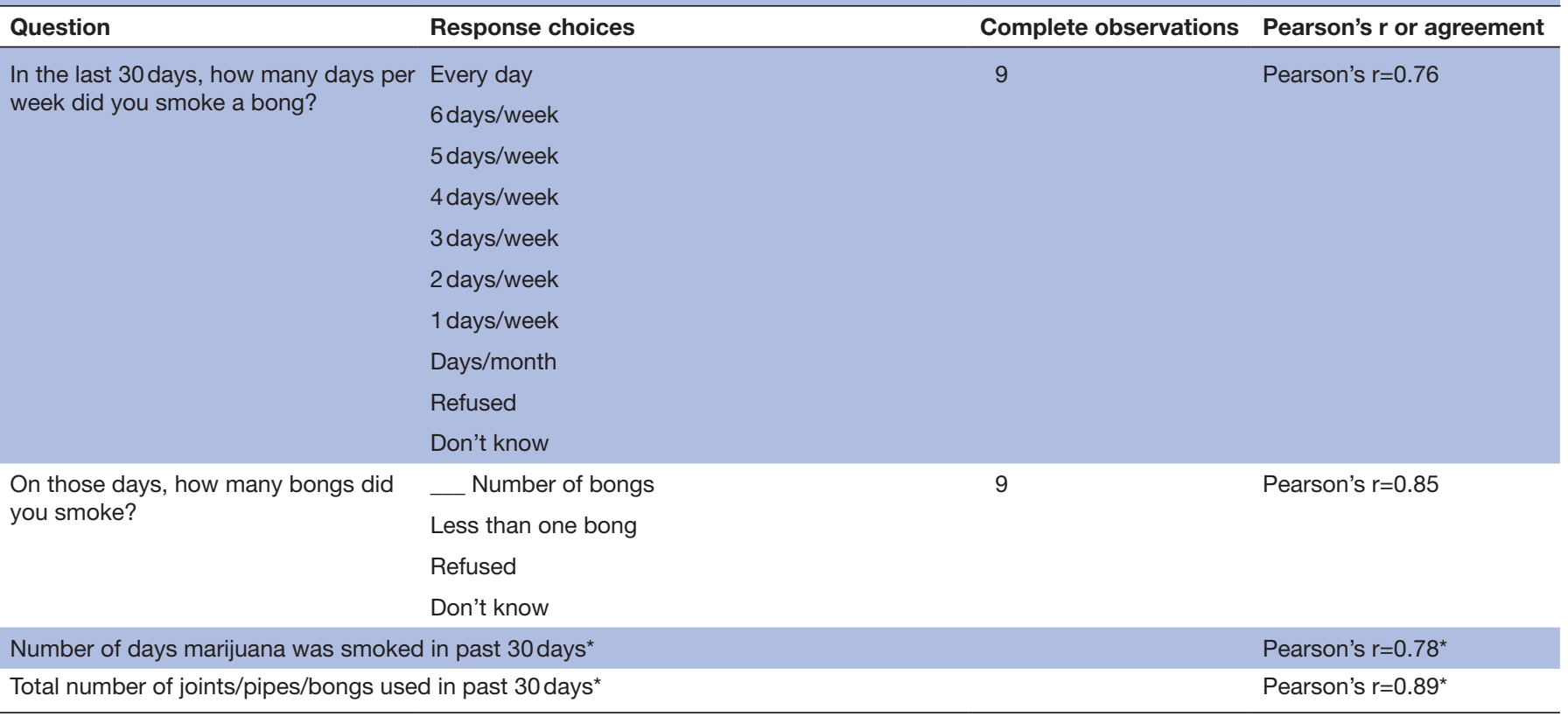

${ }^{*}$ Calculated based on previous questions.

\section{Limitations}

Our study has several limitations. While the sample was national and participants were relatively equally distributed among states with differing status of marijuana legalisation (non-legal, medically legal, recreationally legal), generalisability was limited as the sample mainly consisted of older male veterans with CAD born between 1948 and 1951. The CAT-1 should be tested in a more representative population. While smoking was common among this older population, use of other forms was not common enough to support reliability testing. Tool development to assess other forms of marijuana use among a population with more frequent use is necessary. We did not measure the amount of cannabis used with each form of use. Therefore, our gram-month measure may not accurately capture the total amount used. However, it is unlikely that participants could recall how much cannabis was used each day with each form over the entire month. An overall estimate may be the easiest way to assess overall quantity used.

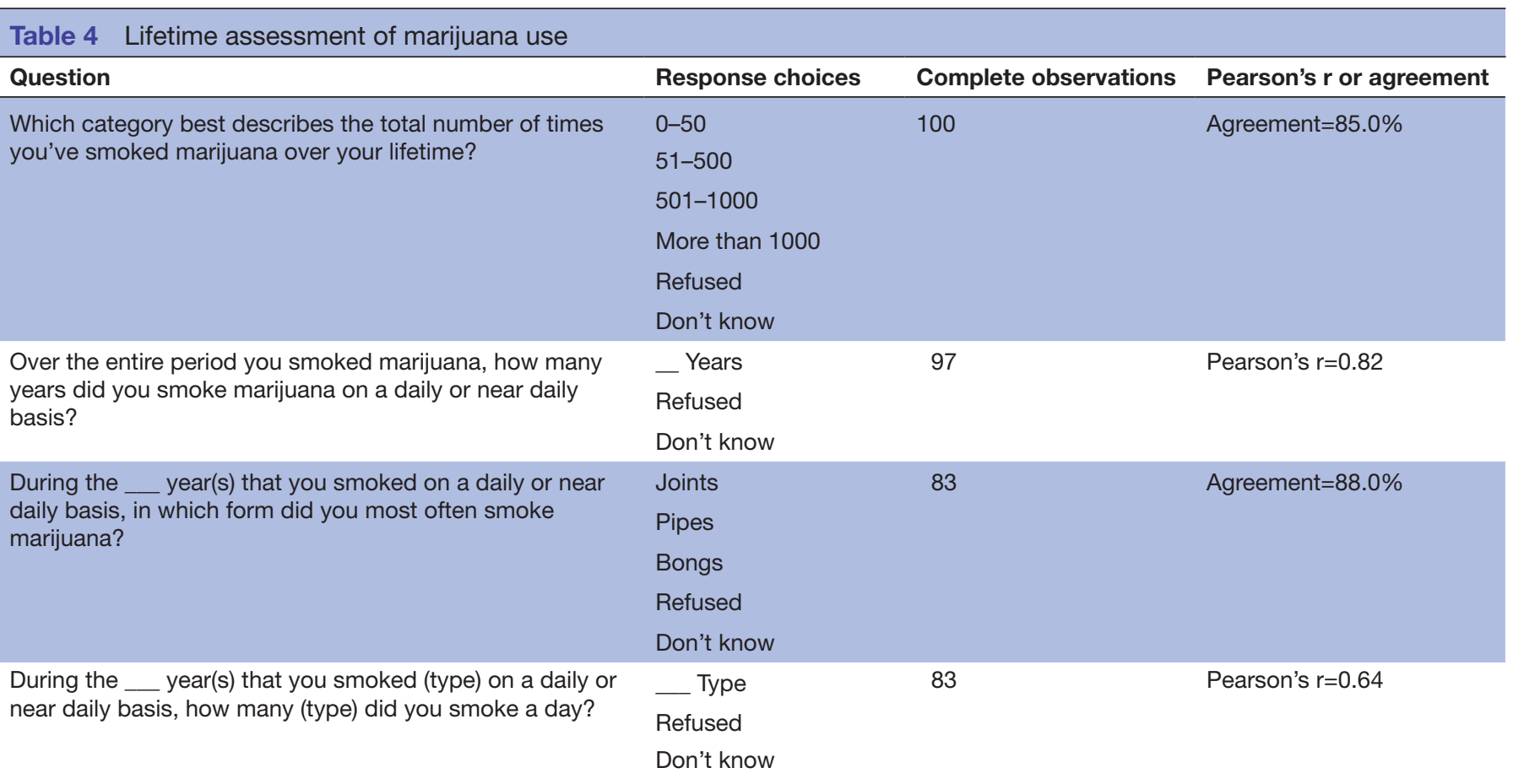


Furthermore, the second survey was administered within 3 days of the initial survey. This was necessary because of the development of 'current use' measures and current use may change with longer intervals. Additionally, as there was no learning or cognitive assessment involved in the exposure tool the risk of recall bias was diminished. However, a longer interval may be desirable for reliability testing of a lifetime use measure. Finally, our tool does not capture potency. In the development phase of the proposal, we found most Veterans did not know the potency of the cannabis they used. As cannabis products become more standardised, assessing potency may become more feasible.

\section{CONCLUSIONS}

The CAT-1 created and tested in this study provides a reliable assessment of current and lifetime use of smoked marijuana. Development of tools to assess other forms of marijuana use is necessary.

Contributors SK had the idea for the study. SK, AA, BC and SS created the study design. SRY and CD collected the data. MV, AA and SK analysed and interpreted the data. SK, AA, SS, BC, SRY, CD and MV wrote and revised the manuscript. All authors critically revised the manuscript and approved the final version for submission. SK is the guarantor.

Funding This research was supported by the National Heart, Lung, and Blood Institute of the National Institutes of Health under grant number R01HL130484-01A1.

Disclaimer The funder had no role in the design and conduct of the study; collection, management, analysis and of the data; preparation, review, or approval of the manuscript; and decision to the manuscript for publication. The views expressed in this article are those of the authors and do not represent the views of the VA or the US government.

Competing interests None declared.

Patient consent for publication Not required.

Ethics approval The UCSF Institutional Review Board approved this study. Provenance and peer review Not commissioned; externally peer reviewed.

Data availability statement Data are available upon reasonable request. The dataset will be made available on https://phprg.ucsf.edu upon request after completion of the main study (NHLBI R01HL130484-01A1). Blank survey tool: Available in appendix.

Open access This is an open access article distributed in accordance with the Creative Commons Attribution Non Commercial (CC BY-NC 4.0) license, which permits others to distribute, remix, adapt, build upon this work non-commercially, and license their derivative works on different terms, provided the original work is properly cited, appropriate credit is given, any changes made indicated, and the use is non-commercial. See: http://creativecommons.org/licenses/by-nc/4.0/.

\section{ORCID iD}

Salomeh Keyhani http://orcid.org/0000-0001-9124-9618

\section{REFERENCES}

1 Governing: The States and Localities. State Marijuana laws in 2018 map. Available: https://www.governing.com/gov-data/safety-justice/ state-marijuana-laws-map-medical-recreational.html [Accessed 29 Mar 2019].

2 Wen H, Hockenberry JM, Cummings JR. The effect of medical marijuana laws on adolescent and adult use of marijuana, alcohol, and other substances. J Health Econ 2015;42:64-80.

3 Keyhani S, Steigerwald S, Ishida J, et al. Risks and benefits of marijuana use: a national survey of U.S. adults. Ann Intern Med 2018;169:282-90.

4 Steigerwald S, Wong PO, Cohen BE, et al. Smoking, Vaping, and use of edibles and other forms of marijuana among U.S. adults. Ann Intern Med 2018;169:890-2.

5 National Academies of Sciences, Engineering, and Medicine. The health effects of cannabis and cannabinoids: the current state of evidence and recommendations for research. Washington, DC: The National Academies Press, 2017.

6 Loflin M, Babson K, Browne K, et al. Assessment of the validity of the CUDIT-R in a subpopulation of cannabis users. Am J Drug Alcohol Abuse 2018;44:19-23. 1.

7 López-Pelayo H, Batalla A, Balcells MM, et al. Assessment of cannabis use disorders: a systematic review of screening and diagnostic instruments. Psychol Med 2015;45:1121-33.

8 Johnston LD, Miech RA, O'Malley PM, et al. Monitoring the future national survey results on drug use 1975-2018: overview, key findings on adolescent drug use. Ann Arbor: Institute for Social Research, University of Michigan, 2019.

9 Hancox RJ, Poulton R, Ely M, et al. Effects of cannabis on lung function: a population-based cohort study. Eur Respir $J$ 2010;35:42-7.

10 Pletcher MJ, Vittinghoff E, Kalhan R, et al. Association between marijuana exposure and pulmonary function over 20 years. JAMA 2012;307:173-81.

11 Center for Behavioral Health Statistics and Quality. 2017 national survey on drug use and health: detailed tables. Rockville, MD: Substance Abuse and Mental Health Services Administration, 2018.

12 Coronary Artery Risk Development in Young Adults. Overview. Available: https://www.cardia.dopm.uab.edu/cardia-overview/ overview-more [Accessed 10 Apr 2019].

13 The Dunedin Study: Dunedin Multidisciplinary Health and Development Unit. Dunedin study: background, the birth of the dunedin study, the study members, the assessments. Available: https://dunedinstudy.otago.ac.nz/studies/assessment-phases/theassessments [Accessed $10 \mathrm{Apr} 2010]$.

14 WHO ASSIST Working Group. The alcohol, smoking and substance involvement screening test (assist): development, reliability and feasibility. Addiction 2002;97:1183-94.

15 Adamson SJ, Sellman JD. A prototype screening instrument for cannabis use disorder: the cannabis use disorders identification test (CUDIT) in an alcohol-dependent clinical sample. Drug Alcohol Rev 2003:22:309-15.

16 Grant BF, Dawson DA. Introduction to the National epidemiologic survey on alcohol and related conditions. Alcohol Res Health 2006;29:74-9.

17 Centers for Disease Control and Prevention (CDC), National Center for Health Statistics (NCHS). National health and nutrition examination survey questionnaire (or examination protocol, or laboratory Protocol). 9. Hyattsville, MD: U.S. Department of Health and Human Services, Centers for Disease Control and Prevention, 2018. https://wwwn.cdc.gov/nchs/nhanes/Default.aspx

18 Robins LN, Wing J, Wittchen HU, et al. The composite international diagnostic interview. An epidemiologic instrument suitable for use in conjunction with different diagnostic systems and in different cultures. Arch Gen Psychiatry 1988;45:1069-77.

19 Readability Formulas. The SMOG readability formula, a simple measure of Gobbledygook, 2019. Available: www. readabilityformulas.com/smog-readability-formula.php [Accessed 11 Mar 2019].

20 Keyhani S, Vali M, Cohen B, et al. A search algorithm for identifying likely users and non-users of marijuana from the free text of the electronic medical record. PLoS One 2018;13:e0193706. 